\title{
EXISTENCE OF SOLUTIONS FOR AN ELLIPTIC BOUNDARY VALUE PROBLEM VIA A GLOBAL MINIMIZATION THEOREM ON HILBERT SPACES
}

\author{
Souad Ayadi, Toufik Moussaoui and Donal O’Regan
}

Abstract. We present a new global minimization theorem on Hilbert spaces which is different from the one in Hofer [7] using the notion of a nonexpansive potential operator. An example is given to illustrate our result.

Mathematics subject classification (2010): 74G65, 46C05, 47H09, 47G40.

Keywords and phrases: minimization theorem, Hilbert spaces, nonexpansive potential operator, BVP.

\section{REFERENCES}

[1] R.P. Agarwal, M. Meehan, D. O'Regan, Fixed Point Theory and Applications, Cambridge University Press, 2004.

[2] R.P. Agarwal, D. O’Regan, D.R. SAhu, Fixed Point Theory for Lipschitzian-Type Mappings with Application, Springer, 2009.

[3] M. Badiale, E. Serra, Semilinear Elliptic Equations for Beginners, Springer, 2011.

[4] J. CHABRows KI, Variational Methods for Potential Operator Equation, Mathematisch Centrum, Amsterdam, 1979.

[5] D.G. CosTA, An Invitation to Variational Methods in Differentiel Equations, Birkhauser Boston, 2007.

[6] D.G De Figueiredo, And S. Solimini, A variational approach to superlinear elliptic problems, Comm. Part. Diff. Equa. 9(7), 1984, 699-717.

[7] H. Hofer, Variational and topological methods in partially ordered Hilbert spaces, Math. Ann. 261(1982), 493-514.

[8] O. Kavian, Introduction à la Théorie des Points Critiques et Applications aux Problèmes Elliptiques, Springer-Verlag, 1993.

[9] S. LiU, Existence of solutions to a superlinear p-Laplacian equation, Electron. J. Differ. Equ., Vol. 2001(2001), No. 66, pp. 1-6.

[10] A. MaO, Y. LI, Infinitely many solutions of superlinear elliptic equation, Abstr. Appl. Anal. 2013, Art. ID 769620, 6 pp.

[11] D. O'Regan, R. Precup, Theorems of Leray - Schauder Type and Application, Gordon and Breach Science Publishers, 2001.

[12] B. RicCERI, Fixed points of nonexpansive potential operators in Hilbert spaces, Fixed Point Theory and Appl. 2012, 2012:123.

[13] E.W.C. VAN Groesen, Variational Methods for Nonlinear Operator Equation, In Nonlinear analysis: Proceeding of the lectures of a Colloquium Nonlinear Analysis.Mathematisch Centrum, Amsterdam, (1976), 100-191.

[14] L. YIn, Y. LiAnG, Q. ZHANG, C. ZHAO, Existence of solutions for a variable exponent system without PS conditions, Electron. J. Differ. Equ. Vol. 2015(2015), No. 63, 23p. 